\title{
Téoros
}

Revue de recherche en tourisme

\section{Cultures régionales et tourisme}

\section{Marc Laplante et Yves Léger}

Volume 7, numéro 1, mars 1988

Cultures régionales et tourisme

URI : https://id.erudit.org/iderudit/1080421ar

DOI : https://doi.org/10.7202/1080421ar

Aller au sommaire du numéro

Éditeur(s)

Université du Québec à Montréal

ISSN

0712-8657 (imprimé)

1923-2705 (numérique)

Découvrir la revue

Citer ce document

Laplante, M. \& Léger, Y. (1988). Cultures régionales et tourisme. Téoros, 7(1),

2-2. https://doi.org/10.7202/1080421ar d'utilisation que vous pouvez consulter en ligne.

https://apropos.erudit.org/fr/usagers/politique-dutilisation/ 
Présentation

\section{Cultures} régionales

Marc Laplante et

Yves Léger

L'intérêt pour la culture est une valeur montante dans nos sociétés matériellement rassásiées. Faut-il s'étonner alors que le tourisme entreprenne des rapprochements avec la culture? Comme le lecteur pourra le constater, ce numéro de Téros est exemplaire a ce propos: treize textes qui, ensemble, tentent de cerner la plupart des questions relatives aux rapports qui unissent tourisme et culture.

Notre revue a tenu un colloque sur le thème: Culture régionales et developpement touristique en mai dernier (ACFAS, Université d'Ottawal. Cette rencontre était la suite d'un colloque similaire tenu un an plus tôt sur: Tourisme et régions (c.f.: Téoros, vol. 5, no 1, mars 1986). Faut-il rappeler combien la région a pris de l'importance dans le paysage touristique quebécois depuis quelques années? ATR et MRC se sont données des plans de développement et des schémas d'aménagement.

Le tourisme y apparaît souvent, associé à des concepts comme l'image de marque d'une région, la spécificité régionale, les produits touristiques régionaux, etc. En arrière-plan de ces notions, Téoros a souhaité que plusieurs intervenants différents se réunissent pour approfondir le concept de culture régionale. Pouvaient-elles, ces cultures, profiter du développement touristique pour s'affirmer, pour se revitaliser? Si oui, comment, à quelles conditions, pour quels touristes?

Notre initiative a porté fruit: les textes qui suivent sont, pour la quasi-totalité, des comptes rendus d'interventions faites au colloque de mai 1987 . Toutefois, si les questions initiales ont pu recevoir certaines réponses, les participants sont peut-être repartis avec davantage de questions car, entre culture et tourisme, les relations ne sont ni évidentes, ni faciles.

M.A. Tremblay a donné le ton au colloque: la culture québécoise passe un mauvais moment: crise d'identité, crise de finalité, anciennes appartenances disloquées; nos ambiguittés et nos incertitudes collectives risquent de produire des images de nous-mêmes très embrouillées. Mais les nouvelles tendances dans les sociétés modernes permettent de fonder des espoirs sur les régions d'ou pourraient naître de nouvelles manifestations de la culture en train de se faire. Est-ce à dire que le tourisme qui préconise un développement des regions arrivera à être facteur de développement culturel?

Jean Stafford, dans un texte savant et original, fait voir avec quelles hésitations et incertitudes la recherche en tourisme a tenté d'explorer le champ culturel. L'analyse de la culture par les sciences sociales semble toujours débordée par son objet et le monde du tourisme n'a pas encore senti le besoin de comprendre les dimensions de cet univers complexe et changeant.

Pourtant, la culture régionale n'apparaît pas toujours aussi compliquée. En géographe entrainé aux études sur le terrain. Marcel Bélanger vous propose une belle démarche qui a l'heureuse originalité de partir du tourisme, des équipements, des récits touristiques pour retrouver des régions culturelles. Si vous le suivez au Lac Etchemin ou ailleurs en Beauce, vous ne douterez plus de l'existence des cultures régionales.
Mais si vous écoutez bien le message de Pierre Dubé qui vit au jour le jour au niveau de la culture dans la capitale nationale, vous comprendrez aussi qu'une région cu/turelle ne voit pas le jour par décret gouvernemental. Les rapports Ottawa-Hull-Outaouais en arrière-plan de l'activité touristique de la région nous obligent à réfléchir sur la culture comme pouvoir, theme des plus tabous chez nous. Line Ouellet, pour sa part, vous fera visiter Ste-Anne de Beaupré comme lieu de patrimoine: à côté des sites et monuments aux valeurs certaines, vous comprendrez comment l'ensemble du patrimoine bâti, si visible pour les étrangers, subit une agression démesurée par le développement touristique. Guy Massicotte, prenant appui sur le cas de la Vallée de la Matapédia, a reconstitué pour nous le long processus par lequel une population doit passer pour se donner une image touristique de marque qui ne trahisse pas sa recherche d'identité. IIfaudra bien conclure, avec ces divers auteurs, que les cultures vécues dans les régions ne se laissent pas facilement récupérer par les opérations souvent expeditives des agents touristiques.

Francois Colbert et Jacques Boisvert d'une part, Marc Laplante de l'autre, ont porté leur attention sur le touriste, ce méconnu. Si un tourisme dit culturel veut prendre forme, celui qui le pratiquera sera un consommateur culturel. Mais quel est donc ce nouveau citoven: un segment de population, nous disent les spécialistes des études de marché, avec ses caracteristiques propres, ses habitudes, ses motivations. Si une région choisit la voie des événements culturels pour attirer des visiteurs, elle devra bien connaitre ce consommateur des temps modernes. Et ce nouveau consommateur, quand il est touriste, vit un moment hors de l'ordinaire. Le comprendre dans ses traits les plus forts et les plus constants pourra obliger les hótes à faire bien des frais pour le satisfaire. Demanderons-nous aux régions de "se donner en spectacle"? Une telle idée semble une parfaite alienation. Mais est-ce si certain!

Regardons bien alors les modes d'action de plusieurs intervenants qui ont su faire des pieds et des mains pour accueillir des visiteurs-touristes sans "perdre leur áme". Cornéliu Kirjan trace une voie pour faire du patrimoine régional une ressource touristique: il nous entraine vers de nouveaux entendements a propos du patrimoine. Claude Moulin ouvre un autre sentier en présentant le programme "rues principales"r de la Fondation canadienne pour la protection du patrimoine: revitalisation des centres-villes et projets touristiques peuvent se rejoindre sans se confondre. Normand Cazelais, avec le cas des auberges au Quebec, donne des aspects trés révélateurs des cultures régionales. René Rivard fait I'historique d'une nouvelle institution: les centres d'interprétation pour nous introduire aux défis qu'entend relever la nouvelle muséologie et Pierre Mayrand nous sensibilise a la philosophie et à la pratique de lapproche des écomusées.

Des intentions aux interventions, la route est longue et les obstacles nombreux. A côté des agents touristiques qui ont essayé de faire de la culture une marchandise, ce numéro de Téoros laisse entendre que le tourisme peut faire alliance avec la culture à condition de se définir comme agent de développement cu/ture/ des régions. /l réussit surtout à montrer, croyons-nous, qu'une telle conception du tourisme n'est plus une utopie. 